\title{
Efetividade clareadora no uso do carvão ativado: revisão de literatura
}

\author{
Whiteness effectiveness in the use of activated charcoal: literature review \\ Eficacia blanqueadora con el uso del carbón activado: revisión de la literatura
}

Recebido: 03/02/2022 | Revisado: 08/02/2022 | Aceito: 16/02/2022 | Publicado: 23/02/2022

\author{
Danielle Duarte Painski Corrêa \\ ORCID: https://orcid.org/0000-0002-3340-0698 \\ Universidade Federal de Santa Catarina, Brasil \\ E-mail: daniellepainski@gmail.com \\ Roberta Pinto Pereira \\ ORCID: https://orcid.org/0000-0003-3479-9992 \\ Universidade Estadual de Campinas, Brasil \\ E-mail: robertapkrohling@gmail.com \\ Sylvio Monteiro Junior \\ ORCID: https://orcid.org/0000-0002-5873-4408 \\ Universidade Federal de Santa Catarina, Brasil \\ E-mail: sylviomj@gmail.com
}

\begin{abstract}
Resumo
Objetivo: Realizar uma revisão de literatura sobre o efeito dos dentifrícios à base de carvão ativado sobre a estrutura dental. Materiais e Métodos: Para o levantamento dos dados foram feitas buscas nas principais bases de dados como Pubmed, LILACS, Scielo e Google acadêmico, com as palavras-chave: "Activated Charcoal”, "Dentifrices", "Tooth Bleaching". Foram selecionados artigos publicados em periódicos nacionais e internacionais entre os anos 2001 à 2021. Resultados: Os dentifrícios à base de carvão ativado são compostos por partículas abrasivas que alteram a superfície do esmalte dental, removendo o pigmento extrínseco. Já os agentes clareadores, agem no pigmento intrínseco do dente, por meio de uma reação oxidativa, clareando de forma efetiva. Conclusão: Os dentifrícios à base de carvão ativado podem causar mudanças de coloração dos dentes devido à remoção de manchas extrínsecas, entretanto o uso de agentes clareadores à base de peróxidos, no clareamento dental, é a estratégia mais indicada, devido à sua eficácia e segurança biológica.
\end{abstract}

Palavras-chave: Carvão ativado; Dentifrícios; Clareamento dental.

\begin{abstract}
Objective: This study aimed to accomplish a literature review on the effect of activated carbon-based toothpastes on the dental structure. Materials and Methods: For data collection, searches were made in the main databases like Pubmed, LILACS, Scielo and Google academic, with the keywords: "Activated Carbon", "Dentifrices", "Tooth whitening". Articles published in national and international journals between the years 2001 to 2021 were selected. Results: Activated charcoal-based toothpastes are composed of abrasive particles that alter the surface of tooth enamel, by removing extrinsic pigments. The whitening agents, on the other hand, act on the intrinsic pigment of the tooth, by means of an oxidative reaction and it whitens the tooth effectively. Conclusion: The activated carbon-based dentifrices can promote dental color changes by extrinsic stains removal. However, the use of peroxide-based agents as teeth bleaching is the most indicated strategy, due to its effectiveness and biological safety.
\end{abstract}

Keywords: Activated charcoal; Dentifrices; Tooth bleaching.

\section{Resumen}

Objetivo: Realizar una revisión bibliográfica sobre el efecto de los dentífricos a base de carbón activado sobre la estructura dental. Materiales y Métodos: Para levantamiento de los datos, fueran hechas buscas en las principales bases de datos como Pubmed, LILACS, Scielo y Google académico, con las palabras clave: "Carbón Activado", "Pasta Dental", "Blanqueamiento Dental". Fueran seleccionados artículos publicados en revistas nacionales e internacionales entre los años 2001 a 2021. Resultados: Los dentífricos a base de carbón activado están compuestos por partículas abrasivas que alteran la superficie del esmalte dental, removiendo los pigmentos extrínsecos. Ja los agentes blanqueadores actúan en el pigmento intrínseco del diente por medio' de una reacción oxidativa, blanqueando de forma efectiva. Conclusión: Los dentífricos a base de carbón activado pueden causar cambios em la coloración de los dientes debido a la remoción de las manchas extrínsecas, entretanto el uso de agentes blanqueadores base de peróxidos en el blanqueamiento dental es la estrategia más indicada, debido a su efectividad y seguridad biológica.

Palabras clave: Carbón activado; Pasta dental; Blanqueamiento dental. 


\section{Introdução}

Um sorriso harmônico é uma característica marcante para definir uma face como atrativa, principalmente em relação à cor dos dentes, a qual pode ser resolvida por meio de práticas restauradoras com resinas compostas, facetas e coroas cerâmicas ou ainda através do clareamento dental, que se tornou popular por ser mais conservador, por tratar-se de um procedimento relativamente simples e promotor de resultados que atendem às expectativas dos pacientes (Penha, et al., 2015).

As alterações na coloração dental podem ser causadas por fatores extrínsecos e intrínsecos. O manchamento intrínseco está relacionado à incorporação de substâncias no interior dos tecidos dentais ou ainda a uma má formação estrutural. Já o manchamento extrínseco relaciona-se ao biofilme cromógeno ou a exposição às substâncias ou hábitos que favorecem a deposição de pigmentos no dente como o tabagismo, alimentos ricos em corantes ou agentes enxaguatórios catiônicos com clorexidina (Watts et al., 2001).

Com o intuito de aumentar a acessibilidade dos pacientes a tratamentos clareadores menos onerosos e que prometem eficácia em um curto período de tempo, o mercado lança produtos clareadores de venda livre, que não precisam de prescrição nem acompanhamento dos profissionais como enxaguatórios e dentifrícios (Jurema, 2018).

Além de promoverem uma limpeza dos dentes pela remoção do biofilme dental, os dentifrícios têm sido modificados a fim de remover e controlar manchas. Isto é possível por pelo menos três maneiras: 1. pela incorporação de abrasivos, que promovem o polimento e remoção de uma fina camada mais superficial do esmalte dental que pode apresentar manchamento; 2. pela adição de peróxido de hidrogênio em suas formulações que penetram e atuam nos cromógenos da estrutura dental; 3. por terem em sua composição clareadores ópticos, que são corantes que se depositam sobre os dentes e podem resultar em um aumento na percepção de clareamento (Alshara, et al., 2014; Demarco, et al., 2009; Iqbal, et al., 2011).

Dentifrícios à base de carvão ou carbono ativado recentemente foram lançados, apresentando em sua composição componentes abrasivos, detergentes, agentes terapêuticos e micropartículas de carvão responsáveis por absorver sujidades e promover higiene bucal especialmente em áreas de difícil acesso. No entanto, a forma, o tamanho e a composição dessas micropartículas pode torná-los mais abrasivos, levando um consequente e indesejado aumento na rugosidade do esmalte (Brooks, et al., 2017; Garza, et al., 2015; Pertiwi, et al., 2017).

Sendo assim, este estudo tem como objetivo realizar uma revisão de literatura a fim de avaliar o efeito de dentifrícios à base de carvão ativado sobre a estrutura dental.

\section{Metodologia}

Com base na metodologia de Honório e Santiago (2021), para a realização desta revisão narrativa de literatura foram utilizados os descritores em ciência da saúde (DeCS/MESH) e seus respectivos termos entry. A coleta de dados foi realizada nas bases eletrônicas: Pubmed, Scielo, Lilacs e Google Acadêmico. A pesquisa foi limitada a artigos publicados nas línguas inglesa e portuguesa, e foi compreendido um intervalo de publicação entre os anos de 2017 até 2021, empregando-se a combinação de palavras-chave para um correto delineamento para o assunto abordado como: "Activated Charcoal", "Dentifrices", "Tooth Bleaching". A busca foi realizada em periódicos nacionais e internacionais com indexação nas bases de dados referidas, de artigos que avaliavam a ação de dentifrícios à base de carvão ativado sobre a superfície dental. Artigos em que o tema não tinha relação com o objetivo desta revisão, relatos de caso e carta ao leitor foram excluídos. 
Quadro 1. Fluxograma para a busca dos artigos.

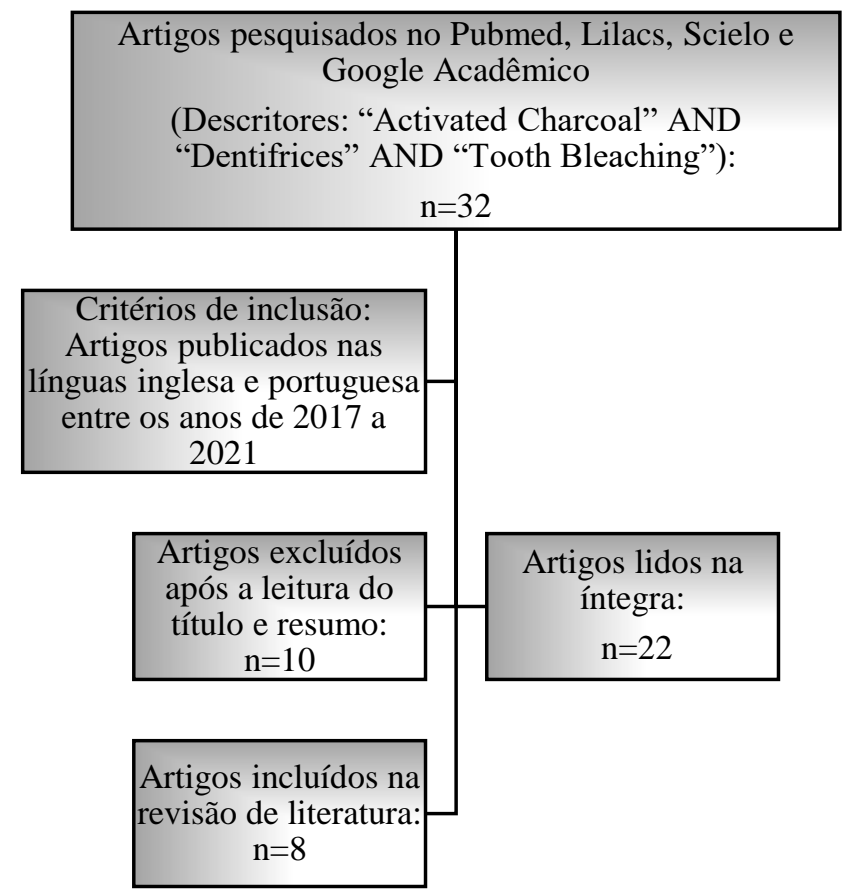

Fonte: Autores (2022).

\section{Revisão de Literatura}

A popularidade dos dentifrícios à base de carvão ativado vem crescendo em diversos países, pois trata-se de um produto de higiene bucal que além de estar na moda, promete uma série de benefícios, entre eles o clareamento dental (Brooks, et al., 2017; Greenwall, et al; 2019).

A tecnologia do clareamento dos dentifrícios à base de carvão ativado se dá por meio do sistema abrasivo, onde ocorre a remoção de manchas extrínsecas e outros depósitos na superfície dental. O potencial de abrasão vai depender da natureza, modo de preparação e tamanho das partículas. Quanto mais abrasivo for, maior será a eficiência na remoção das manchas, e consequentemente, maior a possibilidade de perda de superfície dental e hipersensibilidade (Greenwall, et al; 2019). Além disso, estes dentifrícios podem causar o aumento da rugosidade superficial (Palandi, et al; 2020).

Brooks et al. (2017) realizaram uma revisão de literatura a fim de examinar a eficácia e a segurança do pó e dentifrícios à base de carvão, os autores encontraram divergências quanto ao uso de dentifrícios à base de carvão. Três estudos relataram que o carvão causou efeitos deletérios (abrasão do esmalte e aumento de cárie). Dois estudos mostraram que a escovação com o carvão resultou em redução de cárie comparado à escovação convencional, com ou sem creme dental e um artigo indicou que a utilização do carvão não causou malefícios à higiene oral. Além disso, aos autores avaliaram 50 produtos quanto as informações dos rótulos e promessas terapêuticas. Dentre as alegações cosméticas encontradas: $96 \%$ dos dentifrícios prometeram o clareamento dental, $88 \%$ apresentaram termos atraentes ao consumidor, tais como ecológico, orgânico e puro, em quase 50\% foram encontradas alegações terapêuticas, $46 \%$ prometeram a desintoxicação, $44 \%$ foram considerados antibacterianos ou antissépticos, 30\% alegaram capacidade de remineralização dental, 28\% afirmaram ser pouco abrasivos, 10\% disseram ser recomendado pelo dentista e $8 \%$ prometeram ter flúor na composição. Embora os produtos tenham realizado a propaganda de diversas propriedades, estas não podem ser confirmadas pela literatura.

Vaz et al. (2019) realizaram um estudo randomizado, controlado, duplo cego e in vitro, com o objetivo de comparar a performance do clareamento dental entre diferentes tecnologias após o primeiro uso e depois do uso contínuo. Foram 
selecionados 90 incisivos bovinos, que foram escurecidos em uma solução de chá preto por 18 horas e armazenados em saliva artificial por 7 dias. Após, os dentes foram separados aleatoriamente em 6 grupos para escovação com diferentes dentifrícios: Carvão ativado (Curaprox Black \& White); Covarina azul (Close Up White Attraction Diamond); Peróxido de hidrogênio (Colgate Luminous White Advance); Microesferas abrasivas (Oral B 3D White Perfection); Abrasivos otimizados (Sorriso Xtreme White); Creme dental regular contendo flúor - grupo controle (Colgate Tripla Ação). A escovação dos espécimes ocorreu de maneira padronizada em relação à força, temperatura e tempo. Ocorreram dois ciclos de escovação para cada espécime, um simulou o primeiro uso e o outro, o uso contínuo. Constatou-se que os dentifrícios demonstraram mudanças após o primeiro uso e também depois do uso contínuo. No primeiro uso, apenas os dentifrícios à base de microesferas abrasivas e covarina azul demostraram efeito clareador. Em relação ao uso contínuo, todos os dentifrícios apresentaram efeito clareador comparado ao grupo controle. Os que obtiveram os melhores desempenhos foram os dentifrícios à base de microesferas, peróxido de hidrogênio e covarina azul, nesta ordem. Concluiu-se que todos os dentifrícios clareadores se mostraram eficazes em clarear os dentes após uso contínuo, em comparação ao grupo controle. A diferença entre os dentifrícios testados foi a tecnologia e a abrasividade. Sendo assim, o dentista deve orientar o paciente para a seleção da melhor técnica, buscando o melhor resultado e menor dano para saúde bucal.

Greenwall et al. (2019) realizaram uma revisão de literatura, com o objetivo de fornecer uma visão geral do conhecimento e compreensão dos cremes dentais e pós de carvão ativado. Foram analisadas as seguintes informações: Informação do produto, modo de ação, abrasão, halitose, considerações periodontais, clareamento dental e modo de usar. Na informação do produto, foi sugerido que o modo de ação do carvão ativado ocorre por meio da ligação aos depósitos da superfície dental, com o auxílio da argila bentonita. Como consequência, as placas, bactérias e manchas seriam removidas. Além disso, os autores apresentam que o carvão possui uma alta capacidade de absorção, e isso estaria associado à remoção do flúor e outros íons ativos presentes nos dentifrícios. A ausência destes elementos estaria associada à diminuição da capacidade de reabsorção do esmalte, aumento da susceptibilidade à cárie e ao desgaste dental. Acerca da abrasão dos dentifrícios, mostrou-se uma relação com o tamanho e natureza das partículas de carvão, ou seja, quanto maior o tamanho das partículas, mais abrasivo, mais eficaz na remoção das manchas extrínsecas, mas também maior será o desgaste da superfície dental, podendo desencadear à hipersensibilidade. Em relação à halitose, o carvão demostrou que pode limitar a ação dos aromatizantes e deixar o hálito com um gosto residual de carvão, e por consequência reduzir os efeitos dos dentifrícios na halitose. Quanto às considerações periodontais, foi observado que as partículas de carvão penetram no periodonto, principalmente nas bolsas e defeitos periodontais. No que diz respeito ao clareamento, o carvão removeu o manchamento extrínseco da superfície dental, mas não houve alteração do pigmento intrínseco, pois não há nenhum radical livre que seja capaz de clarear esse tipo de manchamento. Já os agentes clareadores agem de forma intrínseca, clareando o dente de maneira mais efetiva e duradoura. Os autores concluíram que os dentifrícios à base de carvão não possuem embasamento científico para tais propagandas exibidas pelo marketing. Recomenda-se que o dentista indique tratamentos e produtos que sejam testados e mostrem bons resultados na literatura, a fim de ajudar na melhora da saúde bucal de seus pacientes.

Franco et al. (2020) realizaram um estudo laboratorial randomizado, com o objetivo de avaliar as propriedades clareadoras de um pó à base de carvão. Foram utilizados 45 corpos de prova divididos aleatoriamente em 3 grupos: Grupo 1 ou controle - escovação mecânica com creme dental contendo flúor (Colgate Máxima Proteção Anticáries) Grupo 2: escovação mecânica com pó à base de carvão (Whitemax) e Grupo 3: protocolo de clareamento dental utilizando peróxido de carbamida $10 \%$ (Whiteness Perfect). As escovações foram realizadas por uma máquina com padronização da força, tempo e pressão. Já o clareamento, foi realizado com gel peróxido de carbamida 10\% por 3 horas/dia durante 14 dias. Após as escovações e protocolo de clareamento, os espécimes foram armazenados em água destilada a $37^{\circ} \mathrm{C}$ por 23 horas até os procedimentos do dia seguinte. Foram realizadas análises de cor, através de um espectrofotômetro e da rugosidade de superfície, com um rugosímetro e 
microscópio eletrônico de varredura. Ambas foram executadas antes e 14 dias depois dos experimentos. Em relação ao coeficiente de mudança de cor, considerando os parâmetros de Paravina e o limite aceitável proposto por ele, apenas o grupo 3 apresentou mudança de cor estatisticamente significativa. O grupo que foi submetido à escovação com pó à base de carvão apresentou mudança de cor clinicamente perceptível, entretanto, não detectável estatisticamente. Quanto à rugosidade superficial avaliada pelo rugosímetro, não houve diferença significativa em nenhum dos grupos. As imagens encontradas pelo microscópio eletrônico de varredura mostraram uma superfície mais irregular no grupo 1 e uma superfície mais lisa nos grupos 2 e 3 , que foi sugerida à uma maior perda da superfície do esmalte. Concluiu-se com este estudo que embora a escovação utilizando o pó à base de carvão tenha apresentado uma pequena mudança de cor, não foi tão eficaz quanto ao clareamento com peróxido de carbamida $10 \%$.

Palandi et al. (2020) realizaram um estudo experimental in vitro, com o objetivo de avaliar o clareamento com pó de carvão ativado aliado a dentifrícios clareadores ou cremes dentais em comparação ao protocolo de clareamento com peróxido de carbamida 16\%. Foram selecionados 90 incisivos bovinos, separados em 9 grupos com 10 espécimes em cada, de maneira aleatória. Os espécimes foram imersos em solução de chá preto por 24 horas. Os grupos foram divididos para realização das escovações e/ou protocolo de clareamento com os seguintes componentes: carvão, carvão/creme dental regular, carvão/dentifrício clareador, clareamento com peróxido de carbamida, clareamento com peróxido de carbamida/creme dental regular, clareamento com peróxido de carbamida/dentifrício clareador, dentifrício clareador, creme dental regular e sem tratamento (grupo controle). O protocolo de escovação ocorreu por meio de uma máquina que simulou a escovação por 14 dias, com a padronização dos movimentos, tempo, força e frequência. Já o protocolo de clareamento, foi realizado com o gel peróxido de carbamida $16 \%$ durante 4 horas/dia por 14 dias. Após os ciclos de escovação e clareamento, os espécimes foram armazenados em saliva artificial. Foram avaliadas as possíveis alterações de cor através do espectrofotômetro Vita Easyshade, a rugosidade superficial via rugosímetro e a morfologia da superfície do esmalte por meio do microscópio eletrônico de varredura. As análises de cor ocorreram depois do procedimento escurecedor (T0) e 7 dias depois de acabarem os protocolos de escovação e clareamento (TB). Em relação a rugosidade superficial, as análises foram realizadas após procedimento escurecedor e 24 horas depois dos protocolos de clareamento e escovação. Já, com a morfologia da superfície, 3 espécimes de cada grupo experimental foram colocados em um forno e depois ocorreu a pulverização catódica com ouro. Os resultados deste estudo mostraram que a maior mudança de cor ocorreu no clareamento com peróxido de carbamida, independentemente do tipo de escovação que foi realizada. O carvão isolado promoveu mudança de cor maior do que o grupo controle, e quando associado ao creme dental regular e dentifrício clareador não obteve melhoria nos resultados. Os dentifrícios clareadores revelaram mudança de cor maior do que o grupo controle. Quanto à rugosidade de superfície, o peróxido de carbamida, carvão e carvão/creme dental regular demonstraram aumento da rugosidade após os procedimentos, sendo os grupos de carvão os que ocasionaram o maior aumento. O peróxido de carbamida quando associado à dentifrício clareador demonstrou maior rugosidade superficial do que associado à creme dental regular. O dentifrício clareador e creme dental regular promoveram aumento de rugosidade maior do que o grupo controle. Em relação à morfologia superficial do esmalte, o carvão promoveu maior porosidade e depressões na superfície em relação aos outros grupos. Quando associado à dentifrício clareador e creme dental regular as alterações foram mais brandas. Quanto ao peróxido de carbamida isolado, este manteve a superfície semelhante ao grupo controle. Entretanto, quando associado ao grupo controle e dentifrício clareador demostrou aumento da porosidade e depressões. O creme dental regular e dentifrício clareador apenas demonstraram as marcas das cerdas das escovas. Os autores concluíram que a técnica mais adequada de clareamento demonstrado foi o protocolo de clareamento com peróxido de carbamida $10 \%$ de forma isolada, pois apresentou os melhores resultados em relação à mudança de cor, rugosidade de superfície e morfologia do esmalte. Em contrapartida, o carvão promoveu menor mudança de cor que o peróxido de carbamida e causou maiores alterações na superfície e rugosidade do esmalte. 
Machla et al. (2020) realizaram um estudo in vitro com o objetivo de avaliar a abrasividade e as propriedades químicas de dentifrícios à base de carvão ativado. Foram preparados 30 espécimes de dentes humanos e divididos em 5 grupos de acordo com diferentes dentifrícios: Dentifrício NAO (AS, Fyllingsdalen, Noruega), Dentifrício COCO (SkinTechnologies AS Bergen, Noruega), Colgate Max White (dentifrício de referência), Controles positivos (Dentifrício ISO, carvão ativado para uso em laboratório) e controle negativo (água destilada). As escovações foram realizadas através de um equipamento simulador de escovação, padronizada em 10.000 movimentos e um peso de $150 \mathrm{~g}$ para cada amostra. Após as escovações, os espécimes foram submetidos a testes afim de avaliar os efeitos dos dentifrícios, como profundidade média de abrasão, abrasividade relativa da dentina (RDA), rugosidade superficial, adsorção de flúor, pH e detecção de hidrocarbonetos aromáticos. A abrasividade foi avaliada de acordo com a resolução ISO 11609 (onde Colgate Max White foi usado como referência). Os resultados, obtidos pelos autores, mostraram que as profundidades abrasivas médias dos dentifrícios NAO e COCO obtiveram resultados iguais entre si e maiores em relação ao Colgate Max White e o controle negativo; Os valores de abrasividade relativa da dentina dos dentifrícios NAO e COCO e ISSO foram maiores que o valor de Colgate Max White em até 10 vezes; A rugosidade superficial foi maior após a utilização dos dentifrícios NAO, COCO e ISO em relação ao controle negativo; Não houve mudança na média de concentração de fluoreto adsorvida após 24 horas; os dentifrícios NAO e COCO foram considerados alcalinos; O dentifrício NAO mostrou a presença de naftaleno em sua composição. Concluiu-se que os dentifrícios NAO e COCO foram abrasivos dentro dos limites aceitáveis (estabelecidos pela ISO 11609 de acordo com Colgate Max White como referência) e não houve adsorção de flúor. Ainda assim, a utilização de dentifrícios contendo carvão na promoção da saúde bucal e dental é questionado.

Viana et al. (2021) realizaram um estudo in vitro, com o objetivo de avaliar o efeito de dentifrícios à base de carvão ativado sobre o desgaste abrasivo do esmalte e dentina em dentes humanos. Para a realização do estudo, foram preparados 90 espécimes de esmalte e dentina e divididos em 9 grupos $(n=10)$ de acordo com o dentifrício utilizado: G1: Saliva artificial (controle negativo); G2: Dentifrício Elmex Cáries (controle positivo); G3: Dentifrício Colgate Luminous White Carvão Ativado; G4: Dentifrício Colgate Natural Extracts Carvão Ativado; G5: Dentifrício Oral B 3D White Mineral Clean; G6: Dentifrício Curaprox Black is White; G7: Dentifrício Bianco Carbon; G8: Dentifrício Suavetex Natural; G9: Dentifrício Oralgen Nupearl Advanced. Os espécimes foram submetidos a uma ciclagem de erosão, escovação e abrasão por 5 dias. Inicialmente, foi realizada a imersão em solução de ácido cítrico $1 \%$ por 5 minutos e saliva artificial por 60 minutos. Este procedimento ocorreu 4 vezes ao dia, durante 5 dias. Entre o primeiro e o último período de exposição à saliva artificial, foram realizadas escovações 2 vezes ao dia, através de um equipamento simulador de escovação, padronizado em 45 movimentos/15 segundos e força de 1.5 N, totalizando um tempo de 2 minutos. Os espécimes passaram por avaliações de perda de superfície, pH e concentração de flúor. A perda de superfície foi determinada através de um perfilômetro óptico, o $\mathrm{pH}$ foi avaliado por meio de um medidor de $\mathrm{pH}$ e eletrodo e a concentração de flúor através de um eletrodo de íon seletivo. Os resultados, obtidos pelos autores, mostraram que tanto em esmalte, quanto dentina, os grupos G2, G4 e G6 apresentaram valores de perda de superfície significativamente menores do que o grupo controle negativo (saliva artificial); Os grupos G3 e G5 promoveram desgaste dentinário significativamente menor que o grupo controle negativo; Os outros grupos não apresentaram diferenças significativas em relação ao G1; Houve uma correlação negativa entre a perda de superfície e a concentração de flúor nos dentifrícios em ambos os substratos e uma correlação positiva em relação à perda de superfície do esmalte e pH. Os autores concluíram que ambos os substratos apresentaram maior perda de superfície após a escovação com o grupo controle negativo (saliva artificial) quando comparado com os dentifrícios. Entretanto, apenas os grupos G2, G4 e G5 apresentaram proteção adicional contra a perda de superfície.

Torso et al. (2021) realizaram um estudo in vitro, com o objetivo de avaliar o efeito de dentifrícios à base de carvão vegetal na mudança de cor e desgaste superficial de resinas compostas. Para a realização do estudo, foram preparados 60 blocos padronizados de resina composta (cor A2) e divididos em 5 grupos de acordo com o dentifrício ou pó clareador utilizado (n=12): G1: Dentifrício Colgate Total 12; G2: Dentifrício Curaprox Black is White; G3: Dentifrício Suavetex Natural com Carvão 
Ativado; G4: Pó clareador Carvvo; G5: Pó clareador Whitemax. As escovações foram realizadas através de um equipamento simulador de escovação, onde os espécimes foram submetidos à 417 e 5004 ciclos de escovação. A mudança de cor foi avaliada por meio da espectrofotometria, o desgaste superficial foi analisado através da perfilometria e o tamanho das partículas abrasivas foram avaliadas por microscópio eletrônico de varredura. Os resultados mostraram que após 417 ciclos de escovação, os grupos G3 (Dentifrício Suavetex Natural com Carvão Ativado), G4 (Pó clareador Carvvo) e G5 (Pó clareador Whitemax) promoveram maior mudança de cor na resina composta em relação ao G1 (Dentifrício Colgate Total 12). Ou seja, as resinas ficaram mais escuras. Após 5004 ciclos de escovação, todos os grupos provocaram escurecimento na resina composta, exceto G1 (Dentifrício Colgate Total 12); Em ambos os tempos de escovação, os grupos G4 (Pó clareador Carvvo) e G5 (Pó clareador Whitemax) promoveram maior desgaste superficial na resina composta comparado ao G1 (Dentifrício Colgate Total 12); Após 417 ciclos de escovação, G5 (Pó clareador Whitemax) causou maior desgaste superficial na resina composta em relação ao G1 (Dentifrício Colgate Total 12), G2 (Dentifrício Curaprox Black is White) e G3 (Dentifrício Suavetex Natural com Carvão Ativado). Após 5004 ciclos de escovação, não houve diferença significativa nos valores de desgaste superficial na resina composta entre os dentifrícios e pós à base de carvão. A microscopia eletrônica de varredura mostrou partículas abrasivas maiores nos pós quando comparado aos dentifrícios de carvão. Concluiu-se que os dentifrícios à base de carvão promoveram maior escurecimento e desgaste superficial da resina composta em relação aos cremes dentais convencionais comprometendo a longevidade das restaurações de resina composta.

\section{Resultados}

Baseado na coleta de dados realizada nas bases eletrônicas, 32 artigos foram encontrados. Após a leitura do título, 10 estudos foram excluídos e 22 foram selecionados para leitura na íntegra, dos quais 8 estudos relacionados ao tema dentifrícios à base de carvão ativado foram incluídos nesta revisão de literatura (Quadro 2).

Quadro 2. Artigos incluídos na revisão de literatura.

\begin{tabular}{|c|c|c|c|}
\hline ARTIGO & $\begin{array}{l}\text { TIPO DE } \\
\text { ESTUDO }\end{array}$ & RESULTADOS & CONCLUSÃO \\
\hline $\begin{array}{l}\text { Charcoal and charcoal- } \\
\text { based dentifrices: a } \\
\text { literature review. } \\
\text { BROOKS, J.K.; } \\
\text { BASHIRELAHI, N.; } \\
\text { REYNOLDS, M.A, } \\
2017 .\end{array}$ & $\begin{array}{c}\text { Revisão de } \\
\text { literatura }\end{array}$ & $\begin{array}{l}3 \text { estudos relataram que o carvão causou efeitos } \\
\text { deletérios (abrasão do esmalte e aumento de cárie), } 2 \\
\text { estudos mostraram que a escovação com o carvão } \\
\text { resultou em redução de cárie comparado à escovação } \\
\text { convencional, com ou sem creme dental e } 1 \text { estudo } \\
\text { indicou que a utilização do carvão não causou } \\
\text { malefícios à higiene oral }\end{array}$ & $\begin{array}{l}\text { São necessários mais estudos clínicos e } \\
\text { laboratoriais para maiores investigações a } \\
\text { respeito do carvão. Além de ser de extrema } \\
\text { importância que os dentistas alertem seus } \\
\text { pacientes sobre a insuficiente comprovação } \\
\text { científica das propagandas e possíveis riscos que } \\
\text { o carvão pode trazer à saúde bucal. }\end{array}$ \\
\hline $\begin{array}{l}\text { Whitening toothpaste } \\
\text { containing activated } \\
\text { charcoal, blue covarine, } \\
\text { hydrogen peroxide or } \\
\text { microbeads: which one } \\
\text { is the most effective? } \\
\text { VAZ, V.T.P. et al., } \\
\text { 2019. }\end{array}$ & $\begin{array}{l}\text { Estudo in } \\
\quad \text { vitro }\end{array}$ & $\begin{array}{l}\text { Os dentifrícios demostraram mudanças de cor após } \\
\text { o primeiro uso e depois do uso contínuo. No } \\
\text { primeiro uso, apenas os dentifrícios à base de } \\
\text { microesferas abrasivas e covarina azul } \\
\text { demostraram efeito clareador. Em relação ao uso } \\
\text { contínuo, todos os dentifrícios apresentaram efeito } \\
\text { clareador. }\end{array}$ & $\begin{array}{l}\text { Todos os dentifrícios clareadores se mostraram } \\
\text { eficazes em clarear os dentes após uso contínuo. } \\
\text { A diferença entre os dentifrícios foi a tecnologia e } \\
\text { abrasividade. Sendo assim, o dentista deve } \\
\text { orientar o paciente para a seleção da melhor } \\
\text { técnica. }\end{array}$ \\
\hline
\end{tabular}




\begin{tabular}{|c|c|c|c|}
\hline $\begin{array}{l}\text { Charcoal-containing } \\
\text { dentifrices. } \\
\text { GREENWALL, L.H.; } \\
\text { GREENWALL- } \\
\text { COHEN, J.; WILSON, } \\
\text { N.H.F, } 2019 .\end{array}$ & $\begin{array}{c}\text { Revisão de } \\
\text { literatura }\end{array}$ & $\begin{array}{l}\text { 1) A abrasão mostrou uma relação com o tamanho e } \\
\text { a natureza das partículas abrasivas. 2) O carvão } \\
\text { demostrou diminuição dos efeitos dos dentifrícios } \\
\text { no combate à halitose. 3) As partículas de carvão } \\
\text { penetraram no tecido periodontal. } \\
\text { 4) Dentifrícios à base de carvão ativado removeram } \\
\text { apenas o manchamento extrínseco da superfície } \\
\text { dental. }\end{array}$ & $\begin{array}{l}\text { Os dentifrícios à base de carvão ativado não } \\
\text { possuem embasamento científico para as } \\
\text { propagandas exibidas pelo marketing. } \\
\text { Recomenda-se que o dentista indique tratamentos } \\
\text { e produtos que mostrem. }\end{array}$ \\
\hline $\begin{array}{l}\text { The Effect of a } \\
\text { Charcoal-based Powder } \\
\text { for Enamel Dental } \\
\text { Bleaching } \\
\text { FRANCO, M. et al., } \\
\text { 2020. }\end{array}$ & $\begin{array}{c}\text { Estudo in } \\
\text { vitro }\end{array}$ & $\begin{array}{l}\text { 1) O dentifrício à base de carvão ativado apresentou } \\
\text { mudança de cor perceptível, entretanto não detectável } \\
\text { estatisticamente. } \\
\text { 2) Não houve diferença significativa em relação à } \\
\text { rugosidade superficial entre os grupos. 3) A imagem } \\
\text { do microscópio eletrônico de varredura mostrou } \\
\text { maior perda de esmalte após o uso do dentifrício de } \\
\text { carvão ativado. }\end{array}$ & $\begin{array}{c}\text { Embora a escovação utilizando o dentifrício à } \\
\text { base de carvão tenha apresentado uma pequena } \\
\text { mudança de cor, não foi tão eficaz quanto ao } \\
\text { clareamento com peróxido de carbamida } 10 \% \text {. }\end{array}$ \\
\hline $\begin{array}{l}\text { Effects of activated } \\
\text { charcoal powder } \\
\text { combined with } \\
\text { toothpastes on enamel } \\
\text { color change and } \\
\text { surface properties. } \\
\text { PALANDI, S.S. } \text { et al., } \\
\text { 2020. }\end{array}$ & $\begin{array}{c}\text { Estudo in } \\
\text { vitro }\end{array}$ & $\begin{array}{l}\text { 1) O carvão causou maior mudança de cor quando } \\
\text { comparado ao grupo controle. 2) O carvão causou } \\
\text { menor mudança de cor em relação ao dentifrício } \\
\text { regular e clareador. 3) O carvão isolado demostrou } \\
\text { o maior aumento de rugosidade superficial e } \\
\text { alteração de topografia do esmalte. }\end{array}$ & $\begin{array}{l}\text { O carvão promoveu menor alteração de cor que o } \\
\text { peróxido de carbamida e causou maiores } \\
\text { alterações na superfície e rugosidade do esmalte. }\end{array}$ \\
\hline $\begin{array}{l}\text { In vitro abrasivity and } \\
\text { chemical properties of } \\
\text { charcoal-containing } \\
\text { dentifrices. } \\
\text { MACHLA, F. et al., } \\
\text { 2020. }\end{array}$ & $\begin{array}{c}\text { Estudo in } \\
\text { vitro }\end{array}$ & $\begin{array}{l}\text { Os dentifrícios NAO e COCO demostraram } \\
\text { resultados de profundidade abrasiva média iguais } \\
\text { entre si e maiores em relação ao Colgate Max } \\
\text { White e o controle negativo. A rugosidade } \\
\text { superficial foi maior após a utilização dos } \\
\text { dentifrícios NAO, COCO e ISO em relação ao } \\
\text { controle negativo. }\end{array}$ & $\begin{array}{l}\text { Os dentifrícios NAO e COCO foram abrasivos } \\
\text { dentro dos limites aceitáveis e não houve adsorção } \\
\text { de flúor. Ainda assim, o uso de dentifrícios } \\
\text { contendo carvão na promoção da saúde bucal e } \\
\text { dental é questionado. }\end{array}$ \\
\hline $\begin{array}{l}\text { Activated charcoal } \\
\text { toothpastes do not } \\
\text { increase erosive tooth } \\
\text { wear. } \\
\text { VIANA, I.E.L. et al., } \\
\text { 2021. }\end{array}$ & $\begin{array}{l}\text { Estudo in } \\
\text { vitro }\end{array}$ & $\begin{array}{l}\text { Os dentifrícios Elmex Cáries, Colgate Natural } \\
\text { Extracts Carvão Ativado e Curaprox Black is White } \\
\text { apresentaram valores de perda de superfície } \\
\text { significativamente menores no esmalte e dentina do } \\
\text { que no grupo controle negativo. Os dentifrícios } \\
\text { Colgate Luminous White Carvão Ativado e Oral B } \\
\text { 3D White Mineral Clean promoveram desgaste } \\
\text { dentinário significativamente menor do que no } \\
\text { grupo controle negativo. Houve uma correlação } \\
\text { negativa entre a perda de superfície e a } \\
\text { concentração de flúor nos dentifrícios em ambos os } \\
\text { substratos e uma correlação positiva em relação à } \\
\text { perda de superfície do esmalte e pH. }\end{array}$ & $\begin{array}{l}\text { Houve maior perda de superfície dental após a } \\
\text { escovação com saliva artificial quando } \\
\text { comparado com os dentifrícios tanto em esmalte, } \\
\text { quanto em dentina. Entretanto, apenas os } \\
\text { dentifrícios Elmex Cáries, Colgate Natural } \\
\text { Extracts Carvão Ativado e Oral B 3D White } \\
\text { Mineral Clean apresentaram proteção adicional } \\
\text { contra a perda de superfície. }\end{array}$ \\
\hline
\end{tabular}




\begin{tabular}{|c|c|c|c|}
\hline $\begin{array}{c}\text { Charcoal-based } \\
\text { dentifrices: Effect on } \\
\text { color stability and } \\
\text { surface wear of resin } \\
\text { composites. } \\
\text { TORSO, V.H. et al., } \\
2021 .\end{array}$ & $\begin{array}{l}\text { Estudo in } \\
\quad \text { vitro }\end{array}$ & $\begin{array}{l}\text { 1) Após } 417 \text { ciclos de escovação, o Dentifrício } \\
\text { Suavetex Natural com Carvão Ativado, Pó clareador } \\
\text { Carvvo e Pó clareador Whitemax apresentaram maior } \\
\text { escurecimento na resina composta em relação ao } \\
\text { Dentifrício Colgate Total 12; } \\
\text { 2) Após } 5004 \text { ciclos de escovação, todos os grupos } \\
\text { demonstraram escurecimento da resina composta, } \\
\text { exceto o Dentifrício Colgate Total 12; } \\
\text { 3) Em ambos os ciclos de escovação, o Pó clareador } \\
\text { Carvvo e Pó clareador Whitemax promoveram maior } \\
\text { desgaste superficial na resina composta comparado ao } \\
\text { Dentifrício Colgate Total 12; } \\
\text { 4) Após } 417 \text { ciclos de escovação, Pó clareador } \\
\text { Whitemax causou maior desgaste superficial na } \\
\text { resina composta em relação ao Dentifrício Colgate } \\
\text { Total 12, Dentifrício Curaprox Black is White e } \\
\text { Dentifrício Suavetex Natural com Carvão Ativado; } \\
\text { 5) Após } 5004 \text { ciclos de escovação, não houve } \\
\text { diferença significativa nos valores de desgaste } \\
\text { superficial na resina composta entre os dentifrícios e } \\
\text { partículas abrasivas de carvão; } \\
\text { c) A microscopia eletrônica de varredura mostrou }\end{array}$ & $\begin{array}{l}\text { Os dentifrícios à base de carvão demonstraram } \\
\text { maior escurecimento e desgaste superficial da } \\
\text { resina composta do que os cremes dentais } \\
\text { convencionais e assim, estes dentifrícios à base de } \\
\text { carvão podem comprometer a longevidade das } \\
\text { restaurações de resina composta. }\end{array}$ \\
\hline
\end{tabular}

Fonte: Autores (2022).

\section{Discussão}

Uma das principais propagandas dos dentifrícios à base de carvão ativado é o seu potencial em clarear os dentes, sendo uma informação presente na maioria dos produtos comercializados (Brooks, et al., 2017). Sabe-se que após a utilização desses dentifrícios, pode haver uma mudança de coloração dos dentes, dando uma aparência mais clara. Provavelmente, isto possa ser explicado pelo aumento do brilho e refletância do esmalte (Franco, et al., 2020; Greenwall, et al; 2019; Palandi, et al., 2020). Entretanto, os mesmos concordam que há diferenças entre as tecnologias clareadoras do clareamento dental e os dentifrícios à base de carvão ativado.

Os dentifrícios à base de carvão ativado estão entre um dos tipos de dentifrícios abrasivos, que por sua vez, possuem tecnologia clareadora abrasiva. As partículas abrasivas vão alterar a superfície do esmalte dental, removendo manchas extrínsecas e depósitos superficiais. Já o clareamento dental, ocorre por meio de uma reação oxidativa, agindo diretamente sobre o manchamento intrínseco, sendo considerado o método mais eficaz e seguro e responsável pelas maiores mudanças de coloração estatisticamente significativas e ausência de danos clínicos estruturais à superfície dental (Greenwall, et al; 2019; Joiner, 2010; Palandi, et al., 2020).

A associação dos dentifrícios à base de carvão ativado e o clareamento dental não demonstrou melhor eficácia clareadora, entretanto apresentou maior aumento da rugosidade superficial quando comparada a utilização de forma isolada (Palandi, et al., 2020).

O uso indiscriminado dos dentifrícios à base de carvão ativado pode causar algumas mudanças irreversíveis à superfície dental e nas restaurações, como a abrasão, aumento da susceptibilidade à cárie, hipersensibilidade e recessão gengival e risco a longo prazo de manchamento das restaurações estéticas (Brooks, et al., 2017; Hilgenberg, et al., 2011; Quagliatto, et al., 2021). No que diz respeito à abrasão dos dentifrícios, verificou-se uma relação diretamente proporcional entre o tamanho/natureza das partículas abrasivas e o potencial de abrasão. Logo, quanto maior o tamanho das partículas, mais abrasivo, mais eficaz na 
remoção das manchas extrínsecas e maior será o desgaste da superfície dental, podendo desencadear à hipersensibilidade (Greenwall, et al; 2019). No entanto, estas informações estão em desencontro com o estudo de Viana et al. (2021), pois os dentifrícios à base de carvão ativado causaram menor desgaste erosivo no esmalte e dentina quando comparado à escovação com saliva artificial. Já o aumento da susceptibilidade à cárie pode ser explicado pela alta capacidade absorção do carvão ativado. Nos dentifrícios, tal absorção pode remover alguns íons ativos, como o flúor. A ausência de flúor vai ocasionar em uma capacidade limitada de remineralização do esmalte e desta forma, tornar os dentes mais suscetíveis à formação da doença cárie. Além disso, a maioria dos dentifrícios à base de carvão ativado não apresentam em sua composição fluoretos (Greenwall, et al; 2019; Quagliatto, et al., 2021).

Dentre os efeitos deletérios que podem ser causados pelos dentifrícios à base de carvão ativado estão o aumento da rugosidade superficial, maior porosidade e depressões na morfologia superficial do esmalte (Palandi, et al., 2020). Ademais, se utilizado por tempo prolongado, a camada de esmalte vai se tornando mais delgada, podendo levar ao escurecimento dental e causar o efeito contrário do esperado (Rodrigues, et al., 2019). No que diz respeito ao clareamento dental, se utilizado de maneira correta e consciente, podem ocorrer alterações mínimas de aumento da rugosidade superficial, redução da microdureza e desmineralização do esmalte, contudo o potencial remineralizador da saliva é capaz de reverter essas possíveis alterações ao longo do tempo (Agostinho, et al., 2001; Boaventura, et al., 2011; de Freitas, et al., 2002). No que se refere às restaurações cerâmicas, a utilização de dentifrícios de carvão ativado irá causar perda de cor e brilho (Sulaiman, et al., 2020). Em relação às restaurações de resina composta, a longevidade pode ser comprometida devido ao uso de dentifrícios à base de carvão ativado, pois irão ocasionar escurecimento e desgaste superficial (Torso, et al., 2021).

As informações dos dentifrícios clareadores não estão especificadas em suas embalagens, como por exemplo em relação à composição e concentração de componentes. Isso dificulta ainda mais o conhecimento dos consumidores no que diz respeito aos possíveis efeitos e malefícios que estes produtos podem causar. Somado a esse fato, os produtos são facilmente encontrados nas prateleiras, podendo ser utilizado pela população por um longo período de tempo, aumentando a chance de efeitos deletérios e consequentemente, mudanças irreversíveis na superfície dental e restaurações (Rodrigues, et al., 2019).

Verificou se, assim, como relevância clínica deste trabalho, a importância de o cirurgião dentista conhecer a composição, modo de ação e implicações dos dentifrícios à base de carvão ativado, bem como alertar sobre a falta de embasamento científico que comprove as propagandas dos fabricantes e aconselhar os pacientes quanto à escolha da melhor técnica clareadora.

As limitações encontradas foram relacionadas à contemporaneidade do tema, e consequentemente à carência de estudos na literatura. Por ser um tema moderno, os estudos são mais atuais e em pouca quantidade.

Sugere-se, por fim, a realização de novos trabalhos para a melhor compressão dos benefícios e malefícios dos dentifrícios à base de carvão ativado. Recomenda-se a realização de ensaios in vitro e in situ com espécimes de dentes bovinos e humanos, com e sem restaurações, utilização de diferentes dentifrícios à base de carvão ativado e análises de cor e rugosidade superficial à curto e longo prazo.

\section{Conclusão}

Conclui-se, dentro das limitações deste estudo, que os dentifrícios à base de carvão ativado podem ter a capacidade de remoção de manchamentos extrínsecos. Entretanto, o clareamento dental é a estratégia mais indicada para uso clínico devido à sua segurança e efetividade clareadora já consolidada na literatura. Ambas as técnicas causam ao aumento da rugosidade superficial do esmalte. Porém, esse aumento de danos é maior e mais deletério com as pastas de carvão ativado. Ainda assim, é importante que o cirurgião-dentista alerte e desaconselhe os seus pacientes quanto ao uso dos dentifrícios à base de carvão ativado oferecido facilmente nas prateleiras. 


\section{Referências}

Agostinho, F. L. F., Guimarães, R. P., \& Silva, C. H. V. da. (2003). Alterações na microestrutura do esmalte pós-clareamento / Alterations in microstructure in enamel after bleaching. IJD. International Journal of Dentistry, 2(2), 273-278.

Alshara, S., Lippert, F., Eckert, G. J., \& Hara, A. T. (2013). Effectiveness and mode of action of whitening dentifrices on enamel extrinsic stains. Clinical Oral Investigations, 18(2), 563-569.

Boaventura, J. M. C., Padovani, G. C., Lima, J. P. M. de., Brisighello, L. C., \& Andrade, M. F. de [UNESP. (2011). Microdureza e rugosidade superficial do esmalte submetido ao clareamento: uma revisão de literatura. Revista de Odontologia Da Universidade Cidade de São Paulo, 162.

Brooks, J. K., Bashirelahi, N., \& Reynolds, M. A. (2017). Charcoal and charcoal-based dentifrices. The Journal of the American Dental Association, 148(9), $661-670$.

de Freitas, P. M., Basting, R. T., Rodrigues, J. A. L., \& Serra, M. C. (2002). Effects of two 10\% peroxide carbamide bleaching agents on dentin microhardness at different time intervals. Quintessence International (Berlin, Germany: 1985), 33(5), 370-375.

Demarco, F. F., Meireles, S. S., \& Masotti, A. S. (2009). Over-the-counter whitening agents: a concise review. Brazilian Oral Research, 23(1), 64-70.

Franco, M., Uehara, J., Meroni, B., Zuttion, G., \& Cenci, M. (2020). The Effect of a Charcoal-based Powder for Enamel Dental Bleaching. Operative Dentistry.

Garza, L. A., Thompson, G., Cho, S.-H., \& Berzins, D. W. (2016). Effect of toothbrushing on shade and surface roughness of extrinsically stained pressable ceramics. The Journal of Prosthetic Dentistry, 115(4), 489-494.

Greenwall, L. H., Greenwall-Cohen, J., \& Wilson, N. H. F. (2019). Charcoal-containing dentifrices. British Dental Journal, 226(9), 697-700.

Honório, H. M. \& Santiago Júnior, J. F. (2021). Fundamentos das Revisões Sistemáticas em Saúde. Santos Publicações.

Hilgenberg, S. P., Pinto, S. C. S., Farago, P. V., Santos, F. A., \& Wambier, D. S. (2011). Physical-chemical characteristics of whitening toothpaste and evaluation of its effects on enamel roughness. Brazilian Oral Research, 25(4), 288-294.

Kefi, I., Maria, A., Sana, J., Afreen, M., Fareed, M., Sajid, H., \& Nauman, S. (2011). Role of different ingredients of tooth pastes and mouthwashes in oral health. Journal of Esthetic and Restorative, 20(3), 163-170.

Joiner, A. (2010). Whitening toothpastes: A review of the literature. Journal of Dentistry, 38, e17-e24.

Jurema, A. L. B. (2016) "Eficácia de agentes clareadores de venda livre associados ou não ao clareamento com peróxido de carbamida a 10\%”. Dissertação de Mestrado. Universidade estadual paulista Júlio de Mesquita Filho, 11.

Machla, F., Mulic, A., Bruzell, E., Valen, H., \& Stenhagen, I. S. R. (2020). In vitro abrasivity and chemical properties of charcoal-containing dentifrices. Biomaterial Investigations in Dentistry, 7(1), 167-174.

Palandi, S. da S., Kury, M., Picolo, M. Z. D., Coelho, C. S. S., \& Cavalli, V. (2020). Effects of activated charcoal powder combined with toothpastes on enamel color change and surface properties. Journal of Esthetic and Restorative Dentistry, 32(8), 783-790.

Penha, E. S., Pinto, W. T., Santos, R. L. dos., Guênes, G. M. T., Medeiros, L. A. D. M. de, \& Lima, A. M. A. de. (2015). Avaliação de diferentes sistemas de clareamento dental de consultório. Revista Da Faculdade de Odontologia - UPF, 20(3).

Pertiwi, U. I., Eriwati, Y. K., \& Irawan, B. (2017). Surface changes of enamel after brushing with charcoal toothpaste. Journal of Physics: Conference Series, 884.

Quagliato, P. S. (2021). Clareamento dental e técnicas restauradoras para dentes clareados. $1^{\mathrm{a}}$ edição, São Paulo, Santos Publicações.

Rodrigues, B. A. L., Melo, L. S. A. de, Ribeiro, R. A. de O., Nascimento, A. B. L. do, Teixeira, H. M., Rodrigues, B. A. L., Melo, L. S. A. de, Ribeiro, R. A. de O., Nascimento, A. B. L. do, \& Teixeira, H. M. (2019). Avaliação através da tomografia por coerência óptica do esmalte dentário após o uso de dentifrícios clareadores. Revista de Odontologia Da UNESP, 48.

Sulaiman, T. A., Camino, R. N., Cook, R., Delgado, A. J., Roulet, J.-F., \& Clark, W. A. (2020). Time-lasting ceramic stains and glaze: A toothbrush simulation study. Journal of Esthetic and Restorative Dentistry: Official Publication of the American Academy of Esthetic Dentistry, 32(6), $581-585$.

Torso, V. H., Fraga, M. A. A., Lopes, R. M., Aranha, A. C. C., Correr-Sobrinho, L., \& Correr, A. B. (2021). Charcoal-based dentifrices: Effect on color stability and surface wear of resin composites. Journal of Esthetic and Restorative Dentistry, 33(5), 815-823.

Vaz, V. T. P., Jubilato, D. P., Oliveira, M. R. M. de, Bortolatto, J. F., Floros, M. C., Dantas, A. A. R., \& Oliveira JUNIOR, O. B. de. (2019). Whitening toothpaste containing activated charcoal, blue covarine, hydrogen peroxide or microbeads: which one is the most effective? Journal of Applied Oral Science, 27(0).

Viana, I. E. L., Weiss, G. S., Sakae, L. O., Niemeyer, S. H., Borges, A. B., \& Scaramucci, T. (2021). Activated charcoal toothpastes do not increase erosive tooth wear. Journal of Dentistry, 109.

Watts, A., \& Addy, M. (2001). Tooth discolouration and staining: a review of the literature. British Dental Journal, 190(6), 309-316. 